\title{
Bacterial [Cu,Zn]-superoxide dismutase: phylogenetically distinct from the eukaryotic enzyme, and not so rare after all !
}

\author{
J. Simon Kroll, Paul R. Langford, Kathryn E. Wilks and Anthony D. Keil†
}

Author for correspondence: J. Simon Kroll. Tel: +44171 725 6220. Fax: +44 1717256284 . e-mail: S.KROLL@IC.AC.UK

Molecular Infectious Diseases Group, Department of Paediatrics, Imperial College of Science, Technology and Medicine, St Mary's Hospital, London W2 1PG, UK

\begin{abstract}
Copper- and zinc-containing superoxide dismutases ([Cu,Zn]-SODs) are generally considered almost exclusively eukaryotic enzymes, protecting the cytosol and extracellular compartments of higher organisms from damage by oxygen free-radicals. The recent description of a few examples of bacterial forms of the enzyme, located in the periplasm of different Gram-negative micro-organisms, prompted a re-evaluation of this general perception. A PCRbased approach has been developed and used successfully to identify bacterial genes encoding [Cu,Zn]-SOD in a wide range of important human and animal pathogens - members of the Haemophilus, Actinobacillus and Pasteurella (HAP) group, and Neisseria meningitidis. Comparison of [Cu,Zn]-SOD peptide sequences found in Haemophilus ducreyi, Actinobacillus pleuropneumoniae, Actinobacillus actinomycetemcomitans, Pasteurella multocida, and $\mathbf{N}$. meningitidis with previously described bacterial proteins and examples of eukaryotic [Cu,Zn]-SOD has shown that the bacterial proteins constitute a distinct family apparently widely separated in evolutionary terms from the eukaryotic examples. The widespread occurrence of $[\mathrm{Cu}, \mathrm{Zn}]-\mathrm{SOD}$ in the periplasm of bacterial pathogens, appropriately located to dismute exogenously derived superoxide radical anions, suggests that this enzyme may play a role in the interactive biology of organisms with their hosts and so contribute to their capacity to cause disease.
\end{abstract}

Keywords: [Cu, $\mathrm{Zn}]$-superoxide dismutase, bacterial pathogenicity, phylogenetic tree, Haemopbilus-Actinobacillus-Pasteurella, Neisseria

\section{INTRODUCTION}

The metalloenzyme superoxide dismutase (SOD) catalyses the conversion of superoxide radical anion to oxygen and hydrogen peroxide (McCord \& Fridovich, $1969)$ in the first of a series of protective reactions that remove cytotoxic free radicals generated during the reduction of molecular oxygen. Virtually all cells have one

\footnotetext{
+Present address: Western Diagnostic Pathology, Myaree, Western Australia.

Abbreviations: [Cu,Zn]-SOD, [Cu,Zn]-superoxide dismutase; DARWIN, Data Analysis and Retrieval With Indexed Nucleotide/peptide sequences; HAP, Haemophilus-Actinobacillus-Pasteurella; PAM, Percentage Accepted Mutations; SOD, superoxide dismutase; TEMED, $N, N, N^{\prime}, N^{\prime},-$ tetramethylethylenediamine.

The GenBank/EMBL accession numbers for the nucleotide and protein sequences reported in this paper are X83122, X83123, X83124, X83125, X83126.
}

or more cytosolic SODs to scavenge radicals released during aerobic metabolism, while higher eukaryotes produce in addition an extracellular form of the enzyme (Hjalmarsson et al., 1987) presumed to have a cytoprotective function. The enzymes which prokaryotes and eukaryotes produce are, however, strikingly different. Of the many bacterial SODs which have been characterized, two groups can be distinguished on the basis of their central metal cation - manganese [Mn] or iron [Fe]. Both groups exhibit extensive primary sequence and structural similarity, suggesting a divergent evolutionary path from a common ancestor (Grace, 1990). Both are confined to the cytosol. In contrast, while eukaryotes harbour a [Mn]SOD in mitochondria, a copper- and zinc- $[\mathrm{Cu}, \mathrm{Zn}]-$ containing enzyme (constituted as a dimer of identical subunits) is found in the cytosol, while a second, different, $[\mathrm{Cu}, \mathrm{Zn}]-\mathrm{SOD}$ is found as the extracellular form. [Cu,Zn]SODs show no sequence similarity to [Fe]- or [Mn]-SOD, suggesting that the two classes of enzyme arose in- 
dependently (Grace, 1990), perhaps reflecting convergent evolution on an important phenotype.

The discovery that the bacterial endosymbiont of the ponyfish, Photobacterium leiognathi, produced a $[\mathrm{Cu}, \mathrm{Zn}]-$ SOD (Puget \& Michelson, 1974) generated considerable controversy. An early hypothesis of horizontal gene transfer to the bacterium from the host (Bannister \& Parker, 1985) has become increasingly hard to sustain as $[\mathrm{Cu}, \mathrm{Zn}]-\mathrm{SOD}$ genes and/or activities have been discovered in a slowly expanding list of organisms including Caulobacter crescentus (Steinman, 1982), Paracoccus denitrificans (Vignais et al., 1982), some pseudomonads (Steinman, 1985), Brucella abortus (Beck et al., 1900), and Haemophilus influenzae and Haemopbilus parainfluenzae (Kroll et al., 1991). Most recently, a SOD, judged to be a copperand zinc-containing enzyme on the basis of inhibition by cyanide and inactivation by hydrogen peroxide, has been detected in an Eschericbia coli strain (Benov \& Fridovich, 1994).

The observation that the genes cloned from Pho. leiognathi, C. crescentus and the Haemophilus species encode proteins with $\mathrm{N}$-terminal sequences characteristic of leader peptides, suggesting localization outside the cytosol (confirmed as periplasmic in $C$. crescentus and $H$. parainfluenzae) (Steinman, 1987; Steinman \& Ely, 1990; Kroll et al., 1991), further suggests that bacterial [Cu, Zn]-SODs might fulfil a different biological role to the $\mathrm{Fe}$ - or $\mathrm{Mn}$ containing enzymes, more analogous to eukaryotic extracellular $[\mathrm{Cu}, \mathrm{Zn}]-\mathrm{SOD}$ in dismuting exogenously derived superoxide. This might be of particular benefit to organisms colonizing a well-oxygenated environment, or for pathogens exposed to the burst of oxygen free-radicals released in the course of phagocytic cell host defence activity, and in the latter could be conceived as a determinant of virulence. Such generalizing hypotheses cannot, however, be developed while the catalogue of bacterial species making the enzyme remains so small, and the examples so diverse. Our discovery of [Cu, Zn]-SOD in different Haemophilus species that colonize or invade the human respiratory tract (Kroll et al., 1991; Langford et al., 1992) led us to speculate that the enzyme may be much more widely distributed among bacteria than until now appreciated. Here we report the result of a systematic examination of the diverse Haemophilus-ActinobacillusPasteurella (HAP) group of bacteria in an attempt to delineate the species range and diversity of this enzyme as a first step to defining its role in the interactive biology of these human and veterinary bacterial pathogens and their hosts.

\section{METHODS}

Bacterial strains and growth conditions. Strains were selected as clinical or veterinary isolates previously characterized as typical of the species and used in studies of pathogenicity. Actinobacillus pleuropneumoniae strains of different serotypes and a strain of Actinobacillus lignieresii were kindly provided by Professor Ian Smith, Royal Veterinary College, London, UK. Actinobacillus actinomycetemcomitans strain 925 is a clinical isolate kindly provided by Eileen Anderson, Public Health Laboratory Service, Oxford, UK. Strains analysed in greater depth in this
Table 1. Strains used in this work

\begin{tabular}{|lll|}
\hline Species & Strain & \multicolumn{1}{c|}{ Reference } \\
\hline H. parainfuenzae & 1391 & Kroll et al. (1991) \\
H. ducreyi & 35000 & Purcell et al. $(1991)$ \\
H. influenzae (non-typable) & $15 \mathrm{~N}$ & Quentin et al. (1990) \\
A. pleuropneumoniae & $\mathrm{S} 1421$ & Kilian et al. $(1978)$ \\
A. actinomycetemcomitans & $\mathrm{Y} 4$ & Tsai et al. (1979) \\
Pas. multocida & $\mathrm{T} 5$ & Gift from Professor \\
& & I. Smith, Royal \\
& & Veterinary College, \\
N. meningitidis & & London, UK \\
& $\mathrm{MC58}$ & McGuinness et al. \\
E. coli & & (1991) \\
\hline
\end{tabular}

work are identified further in Table 1. Brain-heart infusion, where necessary supplemented with $2 \mu \mathrm{g} \mathrm{NAD} \mathrm{ml} \mathrm{N}^{-1}$ and $10 \mu \mathrm{g}$ haemin $\mathrm{ml}^{-1}$ (for Haemophilus strains) or with NAD alone (for Actinobacillus strains), was used in broth form for liquid and (supplemented with $1 \%, \mathrm{w} / \mathrm{v}$, agar) solid bacterial culture. Broth cultures were propagated by shaking at 200 r.p.m. in air at $37^{\circ} \mathrm{C}$.

Extraction of bacterial cell proteins, gel electrophoresis and detection of SOD. The cell pellet from $25 \mathrm{ml}$ exponentially growing aerobic cultures was broken up by freeze-thawing followed by sonication as previously described by Kroll et al. (1991).

PAGE conditions were $4.5 \%(\mathrm{w} / \mathrm{v})$ stacking gel $(\mathrm{pH} 8.3)$ and $10 \%(\mathrm{w} / \mathrm{v})$ separating gel ( $\mathrm{pH} 8.9)$ using the buffer system of Davis (1964) except that the $\mathrm{pH}$ of the upper buffer was raised to 8.9 with $10 \mathrm{M} \mathrm{NaOH}$.

SOD activity in PAGE gels was visualized by the method of Beauchamp \& Fridovich (1971) as modified by Steinman (1985). When used as an inhibitor of SOD activity, potassium cyanide was added to the riboflavin-TEMED solution to a final concentration of $2 \mathrm{mM}$.

Recombinant DNA methods. Standard methods were used for preparation of chromosomal DNA, restriction analysis, Southern blotting, plasmid cloning and preparation of plasmid DNA (Sambrook et al., 1989). Southern blots were probed to $\sim 80 \%$ stringency in $0.015 \mathrm{M} \mathrm{NaCl}, 0.0015 \mathrm{M}$ sodium citrate, $0 \cdot 1 \%$ SDS at $45^{\circ} \mathrm{C}$ for $1 \mathrm{~h}$ with three changes of buffer prior to autoradiography carried out at $-70^{\circ} \mathrm{C}$.

Amplification of DNA by PCR. Reactions were carried out in a total volume of $100 \mu \mathrm{l}$ containing $100 \mathrm{ng}$ of each primer (Fig. 1), deoxynucleoside triphosphates (each at a concentration of $200 \mu \mathrm{M})$, gelatin $(0.01 \%, \mathrm{w} / \mathrm{v}), \mathrm{MgCl}_{2}(2.5 \mathrm{mM})$, Tris, $\mathrm{pH} 8$ $(10 \mathrm{mM}), \mathrm{KCl}(50 \mathrm{mM})$, and $2 \mathrm{U}$ Taq polymerase (Perkin-Elmer Cetus). The PCR mixture was irradiated with ultraviolet light to cross-link any contaminating DNA before template was added (Sarkar \& Sommer, 1990). Samples were overlaid with mineral oil and processed through 30 cycles $\left[2 \mathrm{~min}\right.$ at $94^{\circ} \mathrm{C}$ (denaturation), $2 \mathrm{~min}$ at $42^{\circ} \mathrm{C}$ (annealing), $2 \mathrm{~min}$ at $72^{\circ} \mathrm{C}$ (extension)].

Nucleotide sequence determination. Nucleotide sequences were determined by the dideoxy chain-termination method (Sanger et al., 1977) using denatured plasmid templates (Hettari \& Sakakai, 1986). $\left[{ }^{35} \mathrm{~S}\right] \mathrm{dATP} \alpha \mathrm{S}$ was used to label the growing strand. The highly processive modified T7 DNA polymerase 
Sequenase (USB) was used with a sequencing kit according to the manufacturer's instructions. Oligonucleotide primers were the universal forward and reverse sequencing primers (New England Biolabs) and oligonucleotides were prepared with a model 380B DNA synthesizer (Applied Biosystems). The Computer program DARwIN (Data Analysis and Retrieval With Indexed Nucleotide/peptide sequences) (Gonnet et al., 1992; Gonnet, 1992, 1994) was used for multiple sequence comparisons.

\section{RESULTS}

Initial attempts to identify cyanide-inhibitable SOD activity (characteristic of $[\mathrm{Cu}, \mathrm{Zn}]-\mathrm{SOD}$ ) in whole cell protein extracts of examples of different HAP species gave unreproducible results, appearing to depend critically on the conditions under which the organisms were grown. Southern hybridization probing with the cloned [Cu, $\mathrm{Zn}]$ SOD gene $(\operatorname{sod} C)$ from $H$. parainfluenzae under conditions that permitted up to $\sim 20 \%$ sequence mismatch gave faint signals with most of the different chromosomal DNAs, suggesting that the species under consideration harboured a version of the gene (data not presented), but these were too weak to allow the probe to be used as a selection tool in a cloning strategy. We therefore developed an approach based on PCR to isolate sodC genes.

The published amino acid sequences of [Cu, $\mathrm{Zn}]-\mathrm{SOD}$ from $H$. influenzae, $H$. parainfluenzae, $C$. crescentus, B. abortus and Pho. leiognathi (Kroll et al., 1991; Steinman, 1982, 1987; Beck et al., 1990) were used to identify conserved regions in the middle (around the enzymically/ structurally important His and Cys residues) (Getzoff $e t$ al., 1989), and near the C-terminus of the enzyme. From these, degenerate oligonucleotide primers $\left(5^{\prime}\right.$ univsod and $3^{\prime}$ univsod) were designed to match the corresponding regions of sodC. Haemophilus codon bias (Kroll et al., 1990) was applied to contain oligonucleotide degeneracy within manageable bounds (8-fold for $5^{\prime}$ univsod, 128 -fold for $3^{\prime}$ univsod, Fig. 1).

$5^{\prime}$ Univsod and $3^{\prime}$ univsod were used in PCR reactions with chromosomal DNA from $H$. influenzae and $H$. parainfluenzae strains known to contain $s o d C$; they amplified a $310 \mathrm{bp}$ fragment as expected from the published sequence (Kroll et al., 1991). Representative strains of HAP bacteria (Table 1) were then examined in an attempt to amplify intervening nucleotide sequence from a $[\mathrm{Cu}, \mathrm{Zn}]-\mathrm{SOD}$ gene. Amongst the multiple products inevitably obtained with degenerate primers of this sort, prominent bands of around $310 \mathrm{bp}$ were seen in each case. No amplification product was found when no template was present, or when chromosomal DNA from E. coli strain DH5 $\alpha$ was used (Fig. 2). In view of the success of this approach, DNA was prepared from other bacterial pathogens of the upper respiratory and genital mucosa and examined in the same way. Strains of Neisseria meningitidis (a Gram-negative pathogen of major medical importance responsible for life-threatening meningococcal septicaemia and meningitis) yielded a comparable amplification product (Fig. 2). No such product was obtained using DNA from examples of the Gram-negative pathogens Neisseria gonorrboeae (three strains examined), Bordetella pertussis (two strains) or Moraxella catarrbalis (three strains), from the Gram-positive pathogen Streptococcus pneumoniae (three strains) or from Mycobacterium tuberculosis (four strains).

Five of the new candidate sodC PCR fragments were cloned and sequenced, and the corresponding deduced amino acid sequence segments compared with the known examples of bacterial [Cu,Zn]-SOD (Figs 3 and 4). The close similarities strongly suggested that in each case a $\operatorname{sod} C$ homologue had been identified. In order to assess whether these genes encoded active [Cu,Zn]-SOD (Kroll et al., 1991), Actinobacillus species were examined in more detail. The cloned fragment from $A$. pleuropneumoniae strain S1421 (with $80.1 \%$ sequence identity to the original Haemophilus probe) was used as a Southern hybridization probe against DNA extracted from a range of serotypes of that species and DNA from other pathogenic Actinobacillus spp. It hybridized strongly to a single chromosomal fragment in all cases, indicating the presence of sodC DNA in each (data not presented). A range of these strains was grown aerobically in rapidly shaking liquid culture, harvested in the late-exponential phase, and whole cell extracts were examined for SOD activity by nondenaturing PAGE. Under the gel conditions described by Steinman (1985), a cyanide-sensitive band of SOD activity characteristic of $[\mathrm{Cu}, \mathrm{Zn}]-\mathrm{SOD}$ was identified in each case (Fig. 5). In similar experiments, the presence of active [Cu,Zn]-SOD was confirmed in all the species with sodC sequence considered here (data not shown).

The set of five new bacterial $[\mathrm{Cu}, \mathrm{Zn}]-\mathrm{SOD}$ sequence segments, all five previously known examples, and a selection of intracellular and extracellular [Cu, $\mathrm{Zn}]-\mathrm{SOD}$ sequence segments from eukaryotes ranging from yeast to humans were compared all-against-all using the interactive system for sequence matching and data analysis (DARWIN) (Gonnet et al., 1992; Gonnet, 1992, 1994), developed and maintained at the Institut für Wissenschaftliches Rechen at the Eidgenössische Technische Hochschule, Zurich, and accessed via the Internet. Using the computer program Mulalignment to demonstrate optimal alignments, it is clear that there are substantial differences between the prokaryotic and eukaryotic examples of this enzyme (Fig. 4). While there are strong similarities between peptide sequences within each phylum, there is otherwise substantial divergence of sequence between the kingdoms, though the sequence from $C$. crescentus is exceptional in aligning rather poorly to any of the rest. There is a suggestion from the sequence alignments that specific peptide domains are characteristic of prokaryotic or eukaryotic $[\mathrm{Cu}, \mathrm{Zn}]-\mathrm{SOD}$, with the implication that secondary and tertiary structures may differ. Clarification of these observations awaits the crystallographic determination of one or more bacterial $[\mathrm{Cu}, \mathrm{Zn}]-S O D$ structures, currently in hand in the cases of the $A$. pleuropneumoniae and Pho. leiognathi proteins (K. Forest, E. Getzoff \& J. Tainer, personal communication).

The DARwin program Phylotree was used to put the differences between peptide sequences on a quantitative 


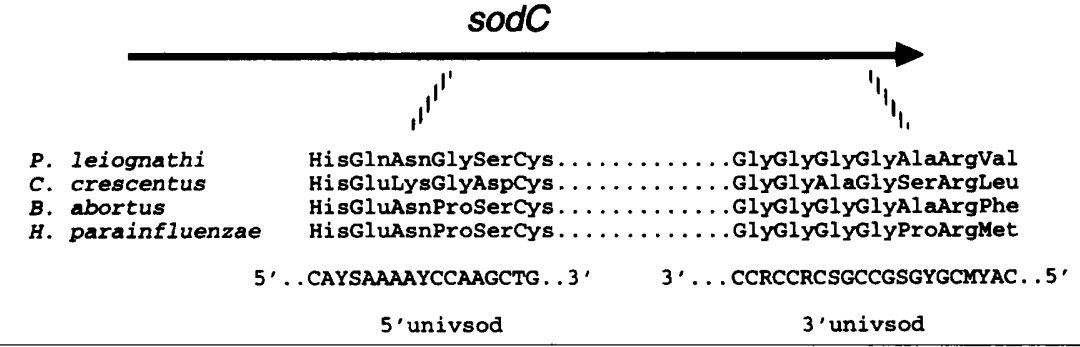

Fig. 1. Design of oligonucleotide primers 5 univsod and $3^{\prime}$ univsod and their location (indicated by dashed lines) within the $H$. parainfluenzae gene sodC (arrow). Primers were synthesized by reverse translation of consensus peptide sequences identified by comparison of published sequences from C. crescentus (Steinman, 1982), B. abortus (Beck et al., 1990), Pho. leiognathi (Steinman, 1987), and $H$. parainfluenzae (Kroll et al., 1991), corresponding (5' univsod) and complementary ( $3^{\prime}$ univsod) to the peptide sequence. Nucleotide degeneracy is indicated by IUPAC code: $R=$ $A$ or $G ; Y=C$ or $T ; M=A$ or $C ; S=C$ or $G$ ).

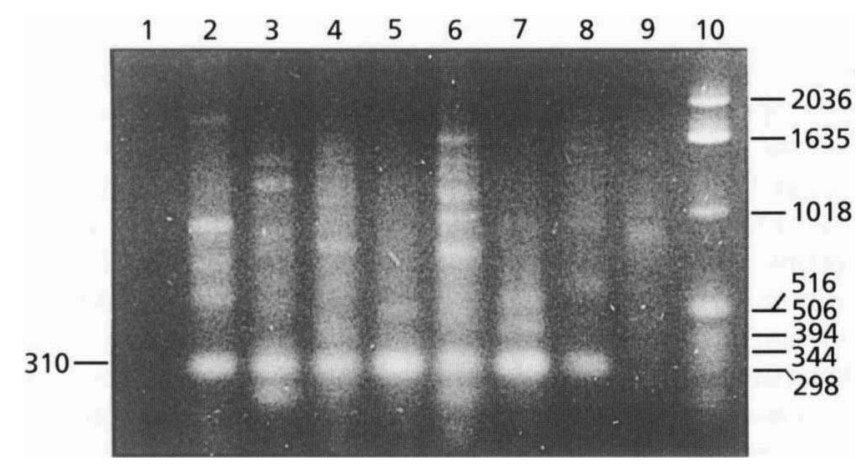

Fig. 2. Ethidium-bromide-stained agarose gel showing electrophoretically separated PCR products generated with $5^{\prime}$ univsod and $3^{\prime}$ univsod and DNA templates as follows: Lanes: 1, no chromosomal DNA; $2, H$. parainfluenzae; 3 , A. pleuropneumoniae; $4, A$. actinomycetemcomitans; $5, N$. meningitidis; 6, Pas. multocida; 7, $H$. ducreyi; 8, biotype IV nontypable $H$. influenzae; $9, E$. coli; 10 , DNA size markers (sizes indicated in bp). The position of the $310 \mathrm{bp}$ fragment corresponding to sodC sequence is indicated.

basis. In the resulting unrooted dendrogram (Fig. 6), pairwise relationships are displayed according to the principle that the length of the tree branch path joining two peptide sequences is in proportion to their degree of homology, calculated as the PAM distance (Percentage Accepted Mutations) separating two sequences (Gonnet et al., 1992; Gonnet, 1994). Short PAM distances thus signify close similarity of sequence, and long distances, correspondingly divergent sequence, and this treatment demonstrates clearly that the prokaryotic and eukaryotic sequences fall into two widely separated lineages, with the unique $C$. crescentus sequence highly divergent from all the other examples.

\section{DISCUSSION}

Our results suggest that the capacity to make $[\mathrm{Cu}, \mathrm{Zn}]-$ SOD, encoded by $\operatorname{sod} C$, is far more widely present in bacteria than has previously been recognized, occurring in diverse colonists and pathogens of the respiratory and genital tracts. Two factors may have contributed to frustrate previous attempts to detect the enzyme in prokaryotes. The first is the selection of conditions under which bacteria are to be cultured, as we have found that the level of $[\mathrm{Cu}, \mathrm{Zn}]-\mathrm{SOD}$ activity can be considerably increased when organisms are grown in shaking liquid media rather than on nutrient agar plates. In agreement with this observation, production of the E. coli putative $[\mathrm{Cu}, \mathrm{Zn}]-\mathrm{SOD}$ is strongly induced during aerobic growth (Benov \& Fridovich, 1994). While the simplest inference is that $\operatorname{sod} C$ transcription is positively regulated by aerobiosis, this awaits further investigation. The second is the selection of conditions under which to run nondenaturing gels to detect $[\mathrm{Cu}, \mathrm{Zn}]-\mathrm{SOD}$ activity. In gels prepared with $\mathrm{pH} 7 \cdot 8$ buffer, the protein migrated very slowly, producing a band of activity that is diffuse and hard to separate from background. Increasing the $\mathrm{pH}$ of the stacking gel to 8.3 and that of the separating gel to 8.9 as suggested by Steinman (1985) has allowed somewhat clearer resolution, though it is possible in some cases that proteins may be denatured and so not detected under these conditions (Steinman, 1985).

The PCR approach using the univsods as oligonucleotide primers has proved a powerful means, complementary to enzymological methods, for finding these genes, successfully allowing amplification of a part of sodC from many organisms and so making straightforward the cloning of whole genes and their flanking sequences. While by this method the range of examples of bacterial $[\mathrm{Cu}, \mathrm{Zn}]-\mathrm{SOD}$ has been greatly widened, failure in amplifying a homologous sequence from a particular organism is of course no proof of its absence. Our lack of success, for example, in finding a sodC gene in E. coli strain DH5 $\alpha$, or in strains of $S$. pneumoniae or M. tuberculosis, may simply reflect critical differences of nucleotide sequence in the part of the gene selected to define the primers in those species. Interesting examples of bacterial species that merit further investigation include Legionella pneumophila and $N$. gonorrboeae. [Cu, $\mathrm{Zn}]-\mathrm{SOD}$ activity has been reported to be present in L. pneumophila (unpublished result of the author cited in Steinman, 1992) but attempts to clone the gene for this have so far failed. We too have so far been unsuccessful in finding sodC in our examination of one strain with the univsod primers, but with a much more substantial choice of sequences to compare as the new bacterial $\operatorname{sod} C$ genes are fully sequenced, new primers selected with a different appropriate codon bias may prove successful in the future. The interest in $N$. gonorrboeae lies 


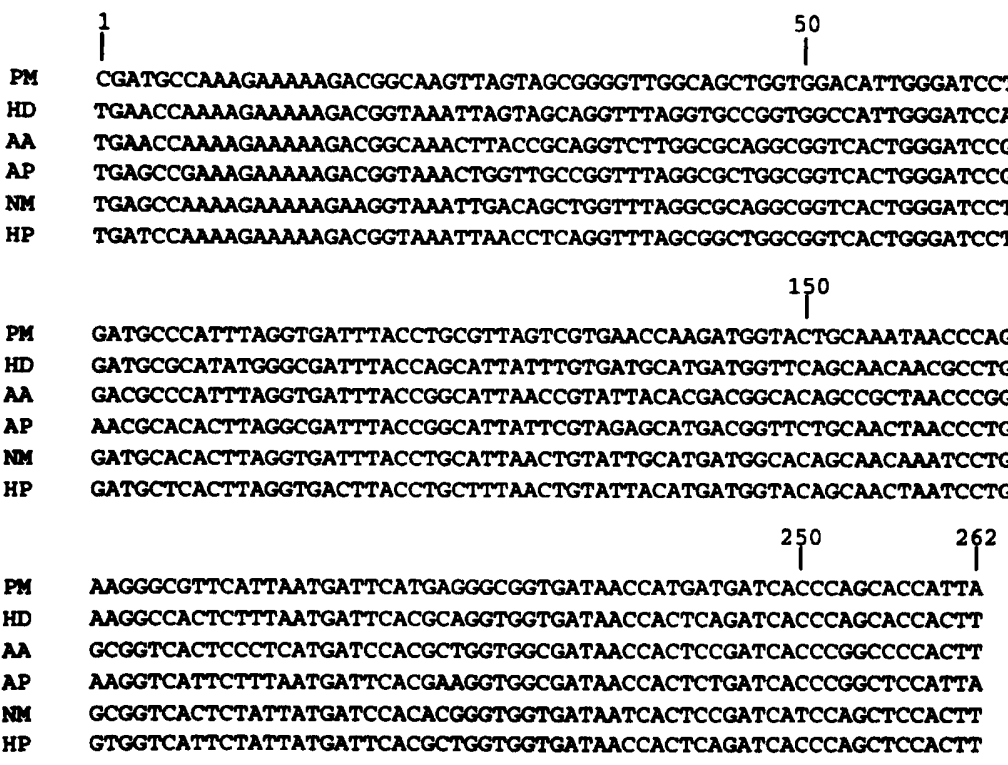

Fig. 3. Nucleotide sequences of sodC DNA fragments generated with $5^{\prime}$ univsod and $3^{\prime}$ univsod from Pas. multocida (PM), $H$. ducreyi (HD), A. actinomycetemcomitans (AA), A. pleuropneumoniae (AP) and $N$. meningitidis (NM), aligned with $H$. parainfluenzae (HP) sodC sequence. Base number 1 is the first following $5^{\prime}$ univsod, the sequence ending with the last base before $3^{\prime}$ univsod.

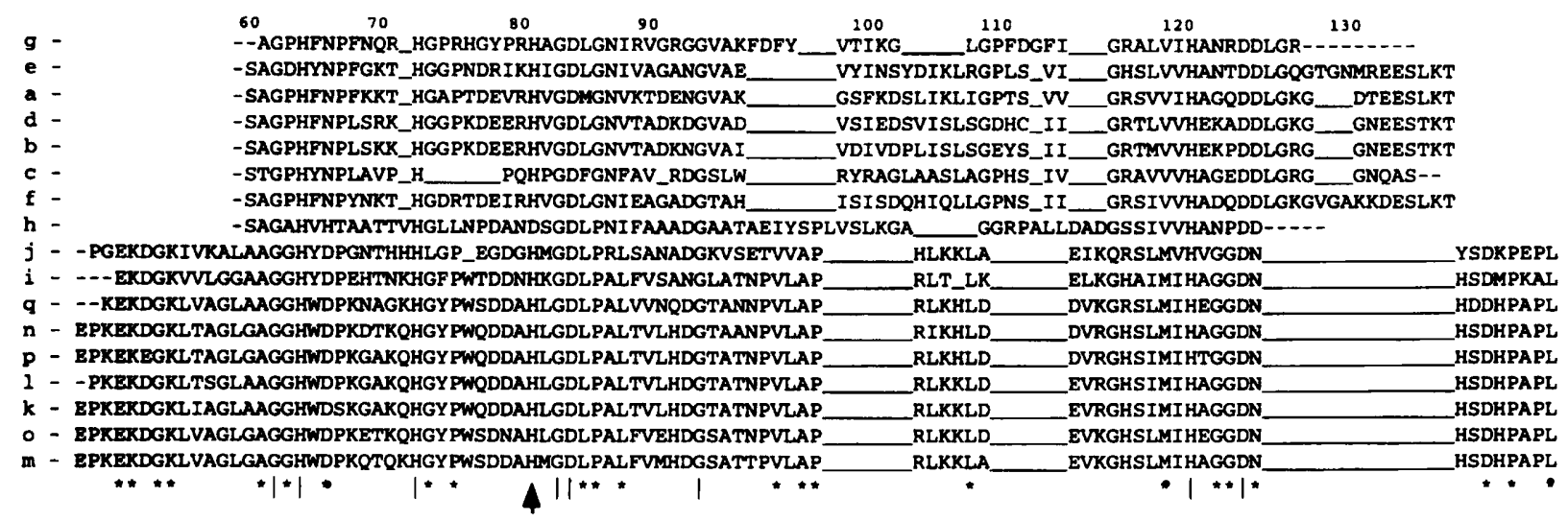

Fig. 4. DARWIN alignment of $[\mathrm{Cu}, \mathrm{Zn}]-S O D$ peptide sequences (Gonnet, 1992). The new bacterial [CU,Zn]-SOD sequence fragments are compared to all other published prokaryotic examples and a selection of intracellular and extracellular eukaryotic [Cu,Zn]-SOD sequences from the corresponding part of the protein as follows (acknowledging published sources of sequence): $a=$ yeast (Johansen et al., 1979); $b=$ bovine (Steinman et al., 1974); $c=$ human (extracellular) (Hjalmarsson et al., 1987); $d=$ human (intracellular) (Barra et al., 1980); e = Onchocerca volvulus (extracellular) (James et al., 1994); $f=O$. volvulus (intracellular) (Henkle et al., 1991); $g=$ Schistosoma mansoni (Simurda et al., 1988); $h=C$. crescentus (Steinman, 1982); $\mathrm{i}=$ Pho. leiognathi (Steinman, 1987); $\mathrm{j}=$ B. abortus (Beck et al., 1990); $\mathrm{k}=\mathrm{H}$. parainfluenzae (Kroll et al., 1991); $l=H$. influenzae type $b$ (Kroll et al., 1991); $m=H$. ducreyi; $n=A$. actinomycetemcomitans; $0=A$. pleuropneumoniae; $p=N$. meningitidis; $q=$ Pas. multocida. Within peptide sequence, continuous lines signify gaps introduced by the computer program to optimize alignment. At the ends of the peptide sequence, dashes signify amino acids for which no meaningful alignment can be made. Vertical lines below the sequence alignment indicate completely conserved amino acids, the arrow indicates a $\mathrm{Zn}$-ligand His invariant except in C. crescentus, and asterisks indicate additional amino acids conserved across all bacterial examples (not including the highly divergent $C$. crescentus peptide sequence). Numbering is based on the human intracellular [Cu,Zn]-SOD as in Getzoff et al. (1989).

in the intriguing observation, long established, that many strains produce only very low levels of SOD despite their efficient survival in an oxygen-free-radical-rich environment (Norrod \& Morse, 1979). This raises the question of whether they make a novel, hard-to-detect [Cu,Zn]-SOD
- perhaps a cytoplasmic version - instead of the usual [Mn]- or [Fe]-enzyme. Although our preliminary studies have failed to amplify sodC DNA from a few strains, this is clearly a problem to be revisited once further primers are available. 

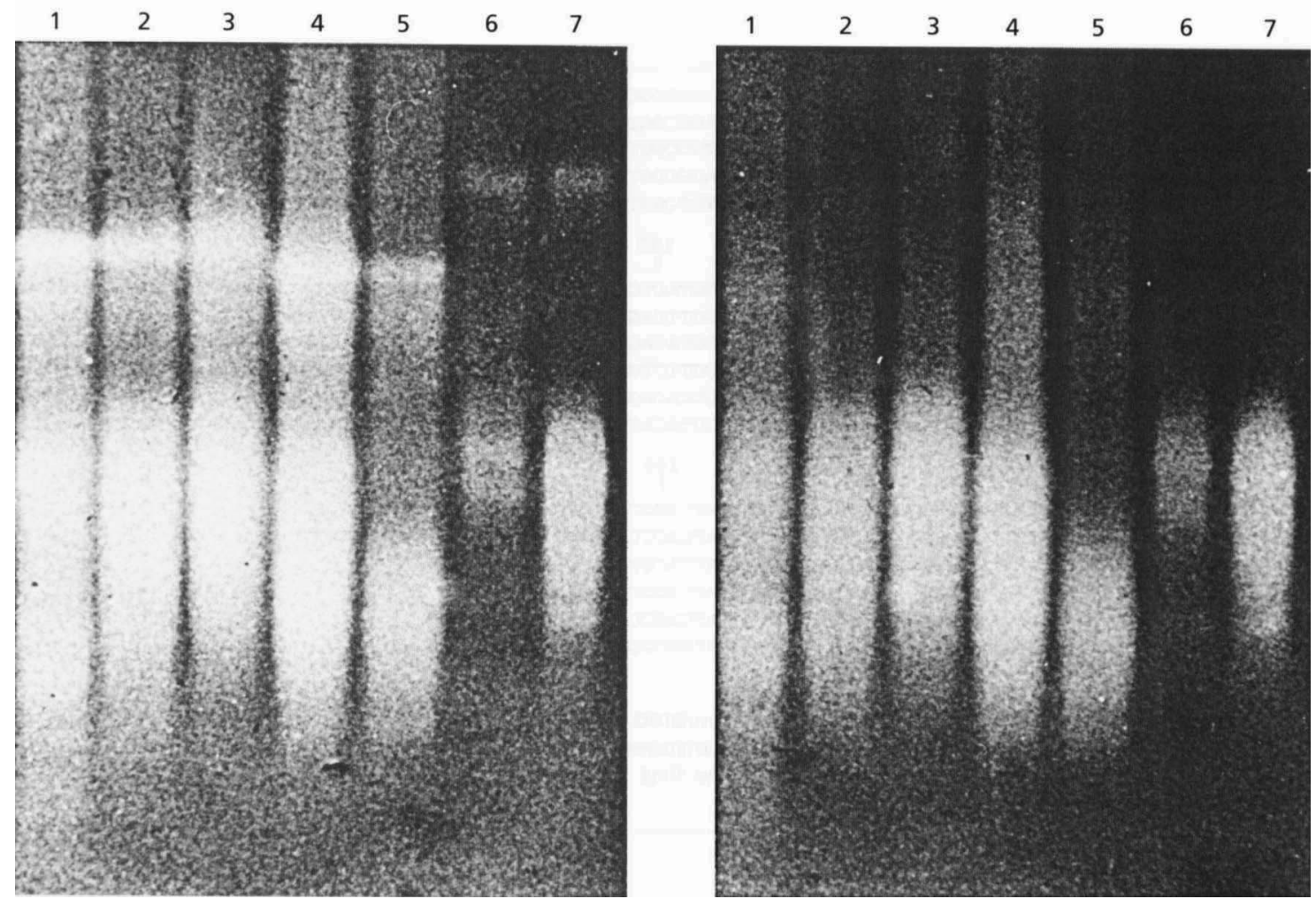

Fig. 5. Paired non-denaturing polyacrylamide gels stained to show SOD activity as an achromatic zone: without selective $[\mathrm{Cu}, \mathrm{Zn}]-\mathrm{SOD}$ inactivation (left) and in the presence of $2 \mathrm{mM} \mathrm{KCN}$ (right). Lanes contain whole cell protein extracts from bacterial species as follows: $1, A$. pleuropneumoniae serotype 3 (strain 51421 ); $2, A$. pleuropneumoniae serotype $5 ; 3, A$. pleuropneumoniae serotype $7 ; 4, A$. pleuropneumoniae serotype $8 ; 5$, A. lignieresii; $6, A$. actinomycetemcomitans strain NCTC 09710; 7, A. actinomycetemcomitans strain 925. The well-defined achromatic band of relatively low mobility, absent in the presence of KCN, represents [Cu,Zn]-SOD; the more diffuse zone, unaffected by $\mathrm{KCN}$, represents [Fe]- or [Mn]-SOD.

Pairwise comparison of the peptide sequence segments now available from ten prokaryotic [Cu, $\mathrm{Zn}]-\mathrm{SODs}$ with each other and with a selection of eukaryotic sequences divides the whole set cleanly into two lineages (Figs 4 and 6). The separation is so clear-cut that it seems safe to draw several conclusions.

First, there is no hint based on peptide sequence that any example of bacterial [Cu, $\mathrm{Zn}]-\mathrm{SOD}$ has arisen as the result of a gene transfer event from a eukaryote. This hypothesis, proposed at the time of the discovery of [Cu, $\mathrm{Zn}]-\mathrm{SOD}$ in the fish endosymbiont Pho. leiognathi (Flohe, 1984), has been regarded with increasing scepticism as other examples have emerged in free-living bacteria. The sequence data presented here, though limited, clearly support the alternative hypothesis that the two sodC families are the descendants - now highly diverged in sequence - of an ancient, ancestral, gene.

Second, while all the bacterial [Cu,Zn]-SODs that have been characterized appear to be extra-cytoplasmically located (Steinman \& Ely, 1990; Kroll et al., 1991; Stabel et al., 1994; and our unpublished results for the Actinobacillus spp. and N. meningitidis), this does not reflect any discernible closer relationship-at least in terms of sequence relatedness or secondary structure - to the extracellular than to the intracellular forms of the eukaryotic enzyme.

Third, of all the bacterial [Cu, Zn]-SODs so far described, that made by $C$. crescentus is the most divergent in terms of peptide sequence, containing as it does unique additional peptide domains not found in either prokaryotic or eukaryotic examples (Fig. 4). So far this has been the only bacterial $[\mathrm{Cu}, \mathrm{Zn}]-\mathrm{SOD}$ subjected to functional analysis (Steinman, 1993) and our results suggest that considerable caution should be used in extrapolating conclusions as to the possible function of periplasmic $[\mathrm{Cu}, \mathrm{Zn}]-\mathrm{SOD}$ in this organism to other bacteria.

With the extensive range of bacterial sequences available here, the identification of residues that are invariant across different $[\mathrm{Cu}, \mathrm{Zn}]-\mathrm{SODs}$, which can therefore be considered as potential fixed points in the determination of protein structure, can be made somewhat more secure. A previous comparison of a set of eukaryotic $[\mathrm{Cu}, \mathrm{Zn}]-$ SOD protein sequences with a single bacterial example (Pho. leiognathi) (Getzoff et al., 1989) classified 23 residues as apparently invariant, in three categories: active site (15 residues), dimer interface ( 4 residues) and $\beta$-barrel (4 residues). Inclusion of Pho. leiognatbi sequence in their comparison allowed Getzoff et al. (1989) to reject 25 


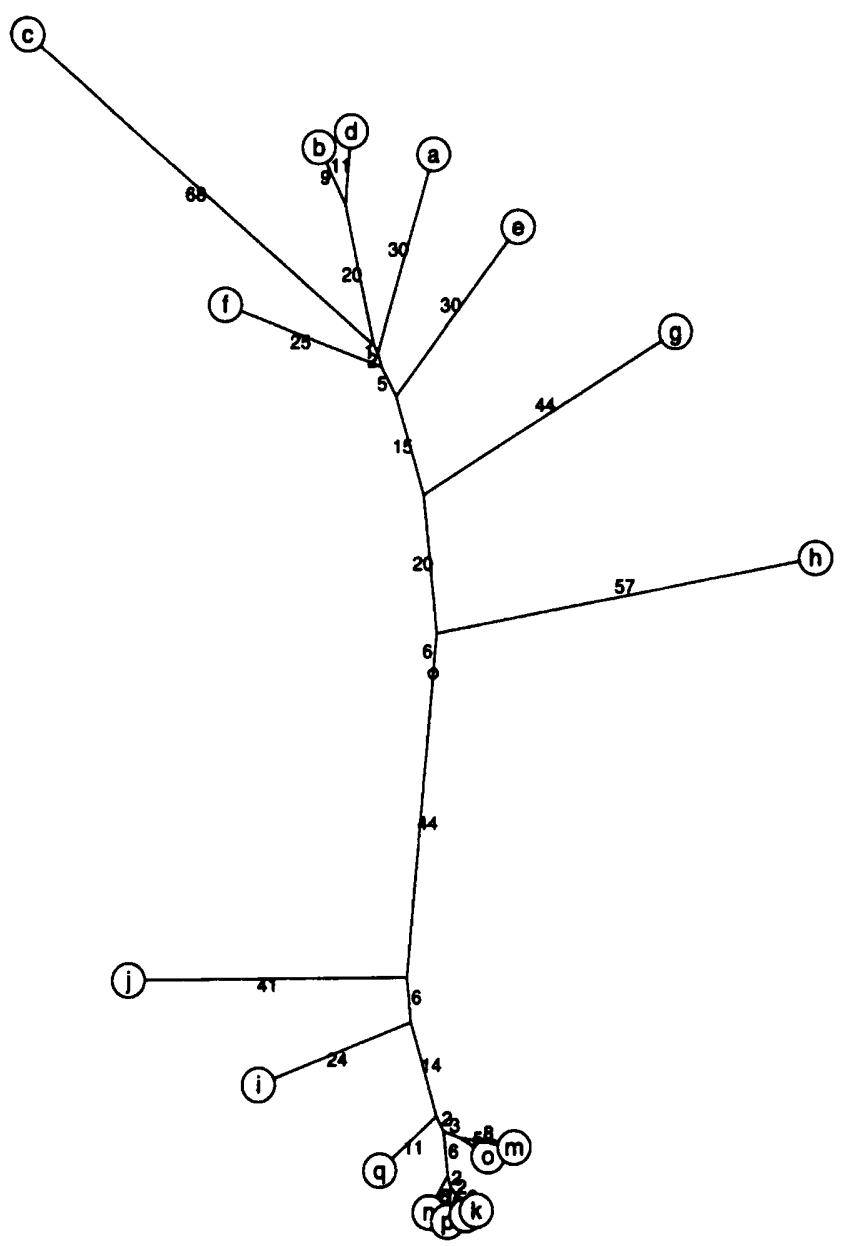

Fig. 6. Graphical representation of peptide sequence differences computed on the basis of PAM distances (Gonnet 1992 , 1994). PAM distances are shown as the relative lengths of each line on the figure (drawn to scale), originating at the centroid (small unlabelled circle). Sequences are identified by single-letter labels as in Fig. 4. Among the bacterial sequences, close similarity, and thus short separating PAM distances, has led to the labels $k, I, p$ and $n$, in that order top-to-bottom, overlying one another.

residues which had previously been considered invariant. Eleven of their 23 residues lie within the region considered here. Metal ligands $\mathrm{His}_{63}, \mathrm{His}_{71}, \mathrm{Asp}_{83}$ and His ${ }_{120}$ are present in all examples, as is $\mathrm{Asp}_{\mathbf{1 2 4}}$, which is involved in maintaining the correct orientation of $\mathrm{Cu}$ and $\mathrm{Zn}$ liganding residues. However $\mathrm{His}_{\mathbf{8 0}}$, identified as a zinccoordinating residue in all previous examples, is replaced with Asp in C. crescentus. As Bordo et al. (1994) observe, though, His is substituted for Asn/Asp 16 residues nearer the $\mathrm{N}$-terminal end of the protein, and together with other changes nearby, this may constitute a 'rescue' mutation in the sodC gene of this organism. Two glycines in the segment under consideration, identified by Getzoff et al. (1989) as involved in stabilization of the structure of the active site (in positions 61 and 82), remain invariant, but $\mathrm{Pro}_{66}$, considered important in orienting $\mathrm{Zn}$ ligands towards the cation, loses invariant status, being replaced by Ser and Thr in $H$. infuenzae and $C$. crescentus, respectively. Gly ${ }_{114}$ is preserved (making allowance for our use of a different alignment program to that used by Getzoff et al., 1989) to form a tight contact across the enzyme dimer interface, but $\mathrm{Leu}_{106}$, thought to be important as a bulky hydrophobic residue maintaining the Greek key $\beta$-barrel fold, is replaced in $C$. crescentus, again anomalous, with Ala. While conclusions like these, agreeing with and extending those of Bordo et al. (1994), suggest that certain residues have key importance in determining structure or function, the unpredictable consequences of substitutions distant from the active site or other key contact regions, as suggested by Bordo $\mathrm{et} \mathrm{al}$. (1994) in the case of the C. crescentus Zn ligand, emphasize the need for the determination of the crystal structure of one or more bacterial [Cu, $\mathrm{Zn}]-\mathrm{SODs}$.

Finally, the discovery that $[\mathrm{Cu}, \mathrm{Zn}]-\mathrm{SOD}$ is quite widespread in mucosal colonists and pathogens rather than a great rarity has biological implications. In each of the organisms that has been found to produce $[\mathrm{Cu}, \mathrm{Zn}]-\mathrm{SOD}$, a conventional [Fe]- or [Mn]-SOD is also present (Fig. 4; Langford et al., 1992; Steinman, 1992, 1985, 1982; Vignais et al., 1982; and our unpublished results). In those new examples of $[\mathrm{Cu}, \mathrm{Zn}]-\mathrm{SOD}$ genes that we have cloned in entirety (the Actinobacillus spp. and N. meningitidis; data not presented), the nucleotide sequence, like those previously published, in each case encodes a protein starting with an N-terminal leader peptide motif, suggesting that the enzyme is extra-cytosolic. As superoxide radical anion generated in the cytosol cannot diffuse across the bacterial inner membrane (Hassan \& Fridovich, 1979), this strongly suggests that while the conventional enzyme disposes of metabolically generated superoxide, the $[\mathrm{Cu}, \mathrm{Zn}]-\mathrm{SOD}$ has a distinct role in the interactive biology of the organism with its environment. A role for surfaceassociated SOD in microbial pathogenicity has been identified for Nocardia asteroides (Beaman \& Beaman, 1990), and suggested for B. abortus (Tatum et al., 1992), while production by $M$. tuberculosis of an extracellular [Fe]-SOD (Zhang et al., 1991) may contribute to the capacity of that organism to survive within macrophages. Pathogens like $A$. pleuropneumoniae, $H$. ducreyi and $N$. meningitidis colonize mucosal surfaces conventionally regarded as aerobic and further excite production of superoxide by phagocytic cells in the course of the inflammatory reaction they provoke. Extra-cytosolic bacterial $[\mathrm{Cu}, \mathrm{Zn}]-\mathrm{SOD}$ may promote their survival by enhancing resistance to the cytotoxic effects of oxygen free-radicals through modulation of the concentrations of superoxide and hydrogen peroxide generated spontaneously in their environment or during the respiratoryburst phase of host defence.

\section{ACKNOWLEDGEMENTS}

We gratefully acknowledge superb technical support from Barbara Loynds, and grants to J.S.K. to fund this work from the Wellcome Trust, the Biotechnology and Biological Sciences Research Council, the British Lung Foundation and Meningitis Research. A.D.K. held an Athelstan and Amy Saw Research Fellowship from the University of Western Australia. This work was presented in preliminary form at the 6th International Conference on Superoxide and Superoxide Dismutase in Kyoto, Japan, October 1993. 


\section{REFERENCES}

Bannister, J. V. \& Parker, M. W. (1985). The presence of a copperzinc superoxide dismutase EC 1.15.1.1 in the bacterium Photobacterium leiognathi; a likely case of gene transfer from eukaryotes to prokaryotes. Proc Natl Acad Sci US A 82, 149-152.

Barra, D., Martini, F., Bannister, J. V., Schinina, M. E., Rotilio, G., Bannister, W. H. \& Bossa, F. (1980). The complete amino acid sequence of human $\mathrm{Cu} / \mathrm{Zn}$ superoxide dismutase. FEBS Lett 120, 53-56.

Beaman, L. \& Beaman, B. L. (1990). Monoclonal antibodies demonstrate that superoxide dismutase contributes to protection of Nocardia asteroides within the intact host. Infect Im mun 58, 3122-3128.

Beauchamp, C. O. \& Fridovich, I. (1971). Superoxide dismutase: improved assays and an assay applicable to acrylamide gels. Anal Biochem 72, 276-287.

Beck, B., Tabatabai, L. B. \& Mayfield, J. E. (1990). A protein isolated from Brucella abortus is a $\mathrm{Cu}-\mathrm{Zn}$ superoxide dismutase. Biochemistry 29, 372-376.

Benov, L. T. \& Fridovich, I. (1994). Escherichia coli expresses a copper-and zinc-containing superoxide dismutase. J Biol Chem 269, 25310-25314.

Bordo, D., Djinovic, K. \& Bolognesi, M. (1994). Conserved patterns in the $\mathrm{Cu}, \mathrm{Zn}$ superoxide dismutase family. $\mathrm{J} \mathrm{Mol} \mathrm{Biol} \mathrm{238,} \mathrm{366-386.}$

Davis, B. J. (1964). Disc electrophoresis. II. Method and applications to human serum proteins. Ann NY Acad Sci USA 121, 404-427.

Flohe, L. (1984). The phylogenetic position of the copper/zinc superoxide dismutase of Photobacterium leiognatbi. In Oxygen Radicals in Chemistry and Biology, pp. 793-799. Edited by W. Bors, M. Saran \& D. Tait. Berlin: Walter de Gruyter.

Getzoff, E. D., Tainer, J. A., Stempien, M. M., Bell, G. I. \& Hallewell, R. A. (1989). Evolution of $\mathrm{CuZn}$ superoxide dismutase and the Greek key beta-barrel structural motif. Proteins 5, 322-336.

Gonnet, G. H. (1992). A tutorial introduction to Computational Biochemistry using DARwIN. Zurich: Informatik E.T.H. (Obtainable from the author at Institut für Wissenschaftliches Rechnen, ETH-Zentrum, CH-8092, Zurich.)

Gonnet, G. H. (1994). New algorithms for the computation of evolutionary phylogenetic trees. In Computational Methods in Genome Research, pp. 153-161. Edited by S. Suhai. New York: Plenum Press.

Gonnet, G. H., Cohen, M. A. \& Benner, S. A. (1992). Exhaustive matching of the entire protein sequence database. Science 256, 1443-1445.

Grace, S. C. (1990). Phylogenetic distribution of superoxide dismutase supports an endosymbiotic origin for chloroplasts and mitochondria. Life Sci 47, 1875-1886.

Hanahan, D. (1983). Studies on transformation of Escherichia coli with plasmids. J Mol Biol 166, 557-580.

Hassan, H. M. \& Fridovich, I. (1979). Paraquat and Escherichia coli. J Biol Chem 254, 10846-10852.

Henkle, K. J., Liebau, E., Muller, S., Bergmann, B. \& Walter, R. D. (1991). Characterization and molecular cloning of a $\mathrm{Cu} / \mathrm{Zn}$ superoxide dismutase from the human parasite Onchocerca volvulus. Infect Immun 59, 2063-2069.

Hettari, M. \& Sakakai, Y. (1986). Dideoxy sequencing method using denatured plasmid templates. Anal Biochem 152, 232-238.

Hjalmarsson, K., Marklund, S. L., Engstrom, A. \& Edlund, T. (1987). Isolation and sequence of complementary DNA encoding human extracellular superoxide dismutase. Proc Natl Acad Sci US A $84,6340-6344$.
James, E. R., McLean, D. C., Jr \& Perler, F. (1994). Molecular cloning of an Oncbocerca volvulus extracellular $\mathrm{Cu}-\mathrm{Zn}$ superoxide dismutase. Infect Immun 62, 713-716.

Johansen, T. T., Overballe-Petersen, C., Martin, B., Hasemann, V. \& Svendsen, I. (1979). The complete amino acid sequence of copper, zinc superoxide dismutase from Saccharomyces cerevisiae. Carlsberg Res Commun 44, 201--217.

Kilian, M., Nicolet, J. \& Biberstein, E. L. (1978). Biochemical and serological characterization of Haemopbilus pleuropneumoniae (Matthews and Pattison 1961) Shope 1964 and proposal of a neotype strain. Int J Syst Bacteriol 28, 20-26.

Kroll, J. S., Loynds, B., Brophy, L. N. \& Moxon, E. R. (1990). The bex locus in encapsulated Haemophilus infuenzae: a chromosomal region involved in capsule polysaccharide export. Mol Microbiol 4, 1853-1862.

Kroll, J. S., Langford, P. R. \& Loynds, B. M. (1991). Copper-zinc superoxide dismutase of Haemophilus influenzae and $H$. parainfluenzae. $J$ Bacteriol 173, 7449-7457.

Langford, P. R., Loynds, B. M. \& Kroll, J. S. (1992). Copper-zinc superoxide dismutase in Haemophilus species. J Gen Microbiol 138, $517-522$.

McCord, J. M. \& Fridovich, I. (1969). Superoxide dismutase. An enzymatic function for erythrocuprein (hemocuprein). $J$ Biol Chem 244, 6049-6055.

McGuinness, B. T., Clarke, I. N., Lambden, P. R., Barlow, A. K., Poolman, J. T., Jones, D. M. \& Heckels, J. E. (1991). Point mutation in meningococcal por $A$ gene associated with increased endemic disease. Lancet 337, 514-516.

Norrod, P. \& Morse, S. A. (1979). Absence of superoxide dismutase in some strains of Neisseria gonorrboeae. Biochem Biopbys Res Commun 90, 1287-1294.

Puget, K. \& Michelson, A. M. (1974). Isolation of a new coppercontaining superoxide dismutase bacteriocuprein. Biochem Biophys Res Commun 58, 830-838.

Purcell, B. K., Richardson, J. A., Radolf, J. D. \& Hansen, E. J. (1991). A temperature-dependent rabbit model for production of dermal lesions by Haemophilus ducreyi. J Infect Dis 164, 359-367.

Quentin, R., Goudeau, A., Wallace, R. J., Jr, Smith, A. L., Selander, R. K. \& Musser, J. M. (1990). Urogenital, maternal and neonatal isolates of Haemophilus infuenqae: identification of unusually virulent serologically non-typable clone families and evidence for a new Haemophilus species. J Gen Microbiol 136, 1203-1209.

Sambrook, J., Fritsch, E. F. \& Maniatis, T. (1989). Molecular Cloning: A Laboratory Manual. Cold Spring Harbor, NY: Cold Spring Harbor Laboratory.

Sanger, F., Nicklen, S. \& Coulson, A. R. (1977). DNA sequencing with chain-terminating inhibitors. Proc Natl Acad Sci USA 74, 5463-5467.

Sarkar, G. \& Sommer, S. S. (1990). Shedding light on PCR contamination. Nature 343, 27.

Simurda, M. C., van Keulen, H., Rekosh, D. M. \& LoVerde, P. T. (1988). Schistosoma mansoni: identification and analysis of an mRNA and a gene encoding superoxide dismutase $(\mathrm{Cu} / \mathrm{Zn})$. Exp Parasitol 67, 73-84.

Stabel, T. J., Sha, Z. \& Mayfield, J. E. (1994). Periplasmic location of Brucella abortus $\mathrm{Cu} / \mathrm{Zn}$ superoxide dismutase. Vet Microbiol 38, 307-314.

Steinman, H. M. (1982). Copper-zinc superoxide dismutase from Caulobacter crescentus CB15. J Biol Chem 257, 10283-10293.

Steinman, H. M. (1985). Bacteriocuprein superoxide dismutases in Pseudomonads. J Bacteriol 162, 1255-1260. 
Steinman, H. M. (1987). Bacteriocuprein superoxide dismutase of Photobacterium leiognathi. J Biol Chem 262, 1882-1887.

Steinman, H. M. (1992). Construction of an Eschericbia coli $\mathrm{K}-12$ strain deleted for manganese and iron superoxide dismutase genes and its use in cloning the iron superoxide dismutase gene of Legionella pneumophila. Mol \& Gen Genet 232, 427-430.

Steinman, H. M. (1993). Function of periplasmic copper-zinc superoxide dismutase in Caulobacter crescentus. J Bacteriol 175, 1198-1202.

Steinman, H. M. \& Ely, B. (1990). Copper-zinc superoxide dismutase of Caulobacter crescentus: cloning, sequencing, and mapping of the gene and periplasmic location of the enzyme. $J$ Bacteriol 172, 2901-2910.

Steinman, H. M., Naik, V. R., Abernethy, J. L. \& Hill, R. L. (1974). Bovine erythrocyte superoxide dismutase. Complete amino acid sequence. J Biol Chem 249, 7326-7338.

Tatum, F. M., Detilleux, P. G., Sacks, J. M. \& Halling, S. M. (1992).
Construction of $\mathrm{Cu}, \mathrm{Zn}$ superoxide dismutase deletion mutants of Brucella abortus: analysis of survival in vitro in epithelial and phagocytic cells and in vivo in mice. Infect Immun 60, 2863-2869.

Tsai, C.-C., McArthur, W. P., Baehni, P. C., Hammond, B. F. \& Taichman, N. S. (1979). Extraction and partial characterization of a leukotoxin from a plaque-derived gram-negative microorganism. Infect Immun 25, 427-439.

Vignais, P. M., Terech, A., Meyer, C. M. \& Henry, M.-F. (1982). Isolation and characterization of a protein with cyanide-sensitive superoxide dismutase activity from the prokaryote Paracoccus denitrificans. Biocbim Biopbys Acta 701, 305-317.

Zhang, Y., Lathigra, R., Garbe, T., Catty, D. \& Young, D. (1991). Cloning and characterisation of the superoxide dismutase gene from Mycobacterium tuberculosis. Mol Microbiol 5, 381-391.

Received 23 February 1995; revised 19 May 1995; accepted 8 June 1995. 